\title{
Effect of fermented feed additive on the broilers' histology/morphology of the GIT, immune status, and microbiota
}

\section{Wentong Peng}

South China Agricultural University

Mir Zulqarnain Talpur

South China Agricultural University

Yuxian Zeng

South China Agricultural University

Peipei Xie

South China Agricultural University

Jincheng Li

South China Agricultural University

Songbo Wang

South China Agricultural University

Lina Wang

South China Agricultural University

Xiaotong Zhu

South China Agricultural University

Ping Gao

South China Agricultural University

Qingyan Jiang

South China Agricultural University

Gang Shu ( $\nabla$ shugang@scau.edu.cn )

South China Agricultural University

Haijun Zhang

Chinese Academy of Agricultural Sciences

\section{Research Article}

Keywords: Fermented feed, Broiler, Intestine, Microbiota

Posted Date: September 1st, 2021

DOl: https://doi.org/10.21203/rs.3.rs-826126/v1 
License: (c) (i) This work is licensed under a Creative Commons Attribution 4.0 International License. Read Full License 


\section{Abstract}

This study was aimed to analyse the effect of a fermented feed additive on the broilers' histology/morphology of the GIT, immune status, and microbiota as an alternative to AGP. Four groups of 288-day-old male and female Arbor Acre broilers were randomly divided (6 replicates in each group each with 12 chicken). Negative control (NC; basal diet), positive control (PC; basal diet +antibiotic virginiamycin 15ppm) one of the 2 fermented feed additives (FFA) diets prepared by adding, fermented feed additive low dose (FFL; basal diet $+0.3 \mathrm{~kg} / \mathrm{t}$ Lactobacillus casei fermented feed additive) and fermented feed additive high dose ( $\mathrm{FFH} ; 3 \mathrm{~kg} / \mathrm{t}$ Lactobacillus casei fermented feed additive). Composition of fermented feed: total bacteria count: $2 \times 10^{9} \mathrm{CFU} / \mathrm{g} \otimes$ Lactic acid $20 \mathrm{mg} / \mathrm{g}$, acetic acid $5 \mathrm{mg} / \mathrm{g}$, succinic acid $7 \mathrm{mg} / \mathrm{g}$, pyruvic acid $0.1 \mathrm{mg} / \mathrm{g}$. The research demonstrated that including fermented feed additives (FFA) in the diet provided overall benefits, FFL and PC diets showed improved (1-21 day) feed conversion ratio (FCR) compared to NC from 0-42 day $(P<0.05)$. FFH and FFL showed improve intestinal morphology within the duodenum, jejunum, and ileum with higher villus height $(\mathrm{VH})$, and villus height to crypt ratio $(\mathrm{VH} / \mathrm{CR})(P<0.05)$. Duodenum and ilium crypt depth was highest in PC and FFL respectively $(P<0.05)$. FFH had a significantly lower thymus weight compared to NC $(P<0.05)$. Furthermore, fermented feeds FFL and FFH influenced the intestinal immunity-related mRNA levels and increased expression of IL-10 $(P<0.05)$. FFL down-regulated the mRNA expressions of IL-1 $\beta$ and TLR4 $(P<0.05)$. Both fermented feeds FFL and FFH positively modulated the composition and variety of cecal microbiota compared to the NC.

\section{Introduction}

Previously, fermentation has been associated with methods that improve the nutritional value of unconventional feed ingredients for broilers. In recent decades, the fermentation process has been employed to produce functional feeds that have the potential to improve histology/morphology of the GIT, immune status, and microbiota status of broiler. After banned from antibiotic growth promoter (AGP), the demand for alternatives in poultry was increased due to the higher demand for antibiotic-free poultry (Yang et al. 2009). Therefore, reducing antibiotic usage and finding other alternatives for antibiotics is an unmet need for animals and human health (Stanton 2013; Wang et al. 2015). Several alternatives were introduced to the market include degrading enzymes, yeast extracts, plant extracts, fermented feed, prebiotics, symbiotics, and probiotics (Aktas et al. 2015; Ivory et al. 2008; Sopková et al. 2017). Fermented feed and probiotics have been evaluated as technically viable substitutes to antibiotics in broiler feed, fermented feeds shown to have growth-promoting effects (Yeh et al. 2018), and improve the palatability of feedstuff, and have positive effects on nutrients utilization and reduce the greenhouse gases (GHG) emission (Gao et al. 2020).

Solid-state fermentation (SSF) is one of the oldest fermentation methods, it mimics the natural environment of the microorganism, it contains a solid matrix that serves both functions: as the source and provides nutrients for microbial growth with a little or no free water (Singhania et al. 2017). Generally, 
in countries such as China, mainly SSF technique is used to neutralize the undesirable effect of antinutritional factors in certain feed ingredients (Wang et al. 2014).

Nutrient absorption, nutrient digestibility, and metabolism have all been linked to the gut microbiota, and thus animal productivity is influenced by microbial composition and diversity; additionally, diet, including feed components and feed additives, can modulate gut microbial composition and diversity (Zhang et al. 2016b). Fermented feed also positively modulated the gut microbiota (Alshelmani et al. 2016; Zhang et al. 2016a), such as hens fed a diet supplemented with Lactobacillus as starter cultures decrease Enterobacteriaceae fecal counts (Loh et al. 2007), while fermented moist feed reduced the number of Coliforms and Streptococci within the broilers' small intestine (Missotten et al. 2013). Several studies have been shown that $L$. casei strains can alter the GIT microbiota and affect the immune response of the host (Aktas et al. 2015; Ivory et al. 2008). Whereas, the broiler GIT microbiota contains hundreds of bacterial species, making traditional culture-based approaches difficult to cultivate and study the composition, diversity, and structure of intestinal microbiota. The 16s rDNA gene sequence has been widely used in recent years in a variety of studies to investigate microbial composition and diversity, as well as their relationship to growth performance (Li et al. 2019) and immunity of animals (Aktas et al. 2015). To the best of our knowledge, there is currently very little information on the effects of fermented feed on cecal microbial composition and diversity in broilers.

The poultry industry thus concentrates on making nutrition more efficient in order to help the alternate of AGP. Based on the evidence presented above, we hypothesize that the use of FFA in broiler chicken diets may modulate cecal microbiota and consequently without affecting growth performance parameters. The present study assumes that FFA can improve the growth performance and immunity. Hence, the present study aimed to test the fermented feed supplementation is linked with improving growth performance, immunity, and compositional or functional changes in the chickens' GIT microbiome.

\section{Materials And Methods}

South China Agricultural University's Animal Care and Use Committee reviewed and approved the protocol (Project number 2019B020218001). All procedures were carried out in accordance with the guidelines in the Ministry of Science and Technology's Guide for Experimental Animals (Guangzhou, China), and every effort was made to minimize suffering.

\section{Preparation of fermented feed}

Our laboratory screened the Lactobacillus casei (C37M41) used in this study. Lactobacillus casei (C37M41) was cultured in de Man, Rogosa, and Sharp (MRS) liquid medium at $37^{\circ} \mathrm{C}$ for $18 \mathrm{~h}$ with shaking at $200 \mathrm{rpm}$. The basal substrate included corn, soybean meal, and wheat bran in 6:2:2 respectively, $5 \%$ yeast extract, $5 \%$ molasses were also mixed and poured into a $500 \mathrm{~mL}$ Erlenmeyer flask with a glass stopper, supplemented with sterile water to achieve a moisture content of $40 \%$. Inoculation of the wet mixed substrate with Lactobacillus casei (C37M41) $\left(1 \times 10^{9} \mathrm{cfu} / \mathrm{g}\right)$ and fermented at $37^{\circ} \mathrm{C}$ for 24 
h. The fermented mixture was placed in a one-way valve plastic bag (Rou Duoduo Biotechnology Co., Beijing, China) after the first stage of fermentation, inoculated with Lactobacillus casei $\left(1 \times 10^{9} \mathrm{cfu} / \mathrm{g}\right)$, and incubated at $37^{\circ} \mathrm{C}$ in anaerobic conditions (the second-stage of fermentation). Controls were inoculated flasks. All of the experimental procedures for uninoculated samples were the identical as for inoculated feed, with the exception of the addition of sterile medium (LB and MRS) rather than of inoculated bacteria. Triplicates of inoculated and uninoculated samples (control) were set up. The inoculated feed fermented for 14 days at $37^{\circ} \mathrm{C}$ under anaerobic conditions. Fermented feed was added to the basal diet, mixed evenly, and then made into pellets. The main content in the fermented feed was total bacteria count $2 \times 10^{9} \mathrm{cfu} / \mathrm{g}$, lactic acid $20 \mathrm{mg} / \mathrm{g}$, acetic acid $5 \mathrm{mg} / \mathrm{g}$, succinic acid $7 \mathrm{mg} / \mathrm{g}$, and pyruvate $0.1 \mathrm{mg} / \mathrm{g}$.

\section{Birds, Diets, and Experimental Design}

The broiler chicks were managed in accordance with Arbor Acre broiler chicken guidelines. The test diet was formulated concerning NRC (1994) and NY/T 33-2004 and combined with the AA broiler feeding manual. Four groups of 288-day-old male and female broiler chickens were divided at random (6 replicates in each group each with 12 chicken). Negative control (NC; basal diet), Positive control (PC; basal diet +antibiotic virginiamycin 15ppm) one of the 2 fermented feed additives (FFA) diets prepared by adding, fermented feed additive low dose (FFL; basal diet $+0.3 \mathrm{~kg} / \mathrm{t} L$. casei fermented feed additive) and fermented feed additive high dose (FFH; $3 \mathrm{~kg} / \mathrm{t} L$. casei fermented feed additive). Broiler chicks were fed and watered ad libitum, and a 243L:1D light regime was maintained. The experiment lasted 42 days, divided into a starter period ( 0 to 21 day) and a finisher period ( 22 to 42 day). The composition and nutrient content of the basic diet is shown in Table 1 . The experimental feed was pelletized and fed in the form of pellets.

\section{Growth Performance}

During the experiment, mortality was recorded daily. On the $21^{\text {st }}$ and $42^{\text {nd }}$ day, body weight (BW) and feed intake were recorded. The average daily feed intake (ADFI), average daily gain (ADG), and feed conversion ratio (FCR) were calculated.

\subsection{Sampling Procedure}

On the $21^{\text {st }}$ and $42^{\text {nd }}$ day, one chicken was randomly selected from each replication, to obtain serum samples, blood samples were collected before slaughtering and centrifuged, which were then stored at $20^{\circ} \mathrm{C}$ for further study. Body weight was recorded after a $12 \mathrm{~h}$ feed withdrawal and sacrificed.

After bleeding and defeathering, full eviscerated weight was measured when all the internal organs were excised (head, neck, claws, trachea, esophagus, stomach, gizzard, gizzard contents, intestines, spleen, pancreas heart, liver, glandular, abdominal fat, full craw and cutin membrane, and gonads). At 30 minutes postmortem, the whole thigh and breast muscle tissue were removed from the animal carcasses. The abdominal fat, thigh muscle and breast muscle (including all of fat visceral region and abdominal cavity) 
were weighed, as a percentage of body weight, the weight percentage of fully eviscerated yield was calculated. Breast muscle, thigh muscle, abdominal fat, and liver weight percentages were calculated as a percentage of the weight of the eviscerated carcass.

The thymus, bursa, and spleen were immediately removed, dried, and individually weighed (g) for each individual, and the ratio of thymus, bursa, and spleen weight: body weight (\%) was calculated, where organ index = (organ weight in grams) / (live weight, in grams) x 100. For the expression analysis of inflammatory factors middle section of the jejunum and ileum tissue were placed in a $2 \mathrm{~mL}$ centrifuge tube, and then quickly frozen in liquid nitrogen and transferred to an ultra-low temperature refrigerator at $-80^{\circ} \mathrm{C}$. For intestinal morphology, the duodenum, jejunum, and ileum were collected $2 \mathrm{~cm}$ each and placed in a $10 \%$ middle $(\mathrm{PH}=7.4)$ fixed in formalin fixative and stored in a refrigerator at $4{ }^{\circ} \mathrm{C}$. Cecal contents were placed in a $1.5 \mathrm{~mL}$ centrifuge tube, quickly frozen in liquid nitrogen, and then transferred to an ultralow temperature refrigerator at $-80^{\circ} \mathrm{C}$ for storage.

\section{Inflammatory Factors in the Intestine}

\section{RNA isolation}

Chicken intestinal tissues were collected, and RNA was extracted according to the manufacturer's instructions. RNA was then purified using the RNEasy Mini kit (QIAGEN), where tissues were homogenized in $600 \mathrm{ml}$ of RLT buffer With Tissue Ruptor that is a handheld rotor-stator homogenizer (Qiagen Inc.), as well as total RNA was eluted in $50 \mu \mathrm{l}$ of DNase-free water before being stored at $-80^{\circ} \mathrm{C}$. A spectrophotometer was used to measure the amount of RNA (NanoDrop Products, Wilmington, DE). Each sample's total RNA (300 ng) was extracted. The Primer Express software program was used to design the probe and primer set for the 28S rRNA and cytokines (PE Applied Biosystems, Foster City, CA). A welldesignated technique was used to quantify chemokine and cytokine mRNA expression. Probes and primers for chemokines and cytokines are listed in Table 2. One-step RT-PCR master mix reagents and TaqMan fast universal PCR master mix were used for the qRT-PCR. The Applied Biosystems 7500 Fast real-time PCR system was used for amplification and detection of specific products, with the following cycle profile: one cycle of $48^{\circ} \mathrm{C}$ for $30 \mathrm{~min}$ and $95^{\circ} \mathrm{C}$ for $20 \mathrm{~s}$ followed by 40 cycles of $95^{\circ} \mathrm{C}$ for $3 \mathrm{~s}$ and $60^{\circ} \mathrm{C}$ for $30 \mathrm{~s}$. The enhanced fluorescence found by the 7500 Fast sequence detection system during PCR amplification was due to hydrolysis of the target-specific probes by the rTth DNA polymerase's $5^{\prime}$ nuclease activity. Normalization was carried out on the housekeeping gene 28S rRNA. For each sample, the correction factor was calculated by dividing the mean threshold cycle (CT) value for the 28S rRNAspecific product in that sample by the overall mean CT value for the $28 \mathrm{~S}$ rRNA-specific product in all samples. The following is how the corrected cytokine mean was calculated: average of each replicate $x$ cytokine slope/28S slope $\times 28 \mathrm{~S}$ correction factor.

\section{Intestinal Morphology}

For intestinal morphology collected duodenum, jejunum, and ileum samples were placed in a $10 \%$ middle $(\mathrm{PH}=7.4)$ fixed in formalin fixative prepared in paraffin sections. Perform HE staining, observe under an 
optical microscope, randomly select 5 discontinuous fields for each slice, and count 3 sets of data for each field. The height of the villi refers to the length from the top of the villi to the base of the villi, and the depth of the crypt refers to the distance from the bottom of the intestinal gland to the base opening between the two villi. Measure villus height (VH), crypt depth (CD), and calculate villus height to crypt depth ratio(VH/CD).

\section{Cecal Microbiota}

\section{DNA Extraction}

Dewar et al. (2013) as previously described, using a QIAamp Fast DNA stool mini kit (Qiagen), microbial DNA was extracted from cecum samples as per manufacturer's guidelines.

The quality and the quantity of harvested DNA were measured using a NanoDrop 2000 UV-vis spectrophotometer (Thermo Scientific, Wilmington, USA); additionally, $1 \%$ agarose gel electrophoresis was used to ensure DNA quality. 338 F (5-ACTCCTACGGGAGGCAGCA-3) and 806 R (5GGACTACHVGGGTWTCTAAT-3) were used to amplify the V3-V4 hypervariable regions of the bacterial 16S rRNA gene. A thermocycler PCR system (Gene Amp 9700, ABI, USA) was used to conduct PCR and the reactions were performed in triplicates: $20 \mu \mathrm{L}$ mixture, containing $4 \mu \mathrm{L}$ of $5^{\circ} \emptyset$ FastPfu Buffer, $2 \mu \mathrm{L}$ of $2.5 \mathrm{mmol} / \mathrm{L}$ dNTPs, $0.8 \mu \mathrm{L}$ of each primer $(5 \mu \mathrm{mol} / \mathrm{L}), 0.4 \mu \mathrm{L}$ of FastPfu Polymerase, and $10 \mathrm{ng}$ of template DNA. To purify the extracted PCR products from a $2 \%$ agarose gel, the AxyPrep DNA Gel Extraction Kit (Axygen Biosciences, Union City, CA, USA) was used, which were then quantified using QuantiFluor-ST (Promega, USA) according to the manufacturer's guidelines.

\section{Pyrosequencing and Bacterial Data Processing}

According to Majorbio Bio-Pharm Technology Co. Ltd, Shanghai, China, purified amplicons were pooled and sequenced in equimolar concentrations on an Illumina MiSeq PE300 platform (Illumina, San Diego, USA). The sequencing results were subjected to bioinformatics analysis. Quality-filtered by Trimmomatic and FLASH software with the following criteria were the established raw fastq sequences: (i) bases with a score of less than $<20$ were excluded, and at any site with an average quality, the reads were truncatedscore $<20$ across a 50-bp sliding window; (ii) Trimmomatic software was used to delete truncated reads that were less than $50 \mathrm{bp}$ in length; (iii) reads of up to 2 mismatched nucleotides and more than 0 barcode mismatches were discarded; (iv) using the FLASH programme, the merged reads were removed; additionally, sequences that overlapped longer than $10 \mathrm{bp}$ were assembled using their overlap sequences; $(v)$ readings that have not been assembled have been excluded. After this, highquality sequences acquired were paired with samples based on their barcodes, clustering these reads with up to 97 percent similarities in operational taxonomic units using $U$ search (version 7.1). Then, using the Ribosomal Database Project classifier algorithm, the chimaera and singletons were eliminated and allocated to taxa. A BLAST search for taxonomic classification was performed using QIIME at the 70 percent confidence level in the SILVA database (version 1.8.0). The taxonomic composition was investigated at the phylum, family, class, genus, and species levels using Vegan packages in R. Principal 
coordinate analysis(PCA) of the complete diversity of microbial communities based on species levels based on Bray-Curtis distance was managed by R; (Xia and Wishart 2011).

\section{Statistical Analysis}

Data regarding growth performance, production performance, haematological parameters, carcass, and immunological parameters were analysed using SPSS software (IBM Corp. IBM SPSS Statistics for Windows, Version 23.0. Armonk, NY, USA). GraphPad Prism 7.0 software (Chicago, IL, USA). The data are presented as mean \pm SEM. $P \leq 0.05$ was considered to be statistically significant. Prior to variance analysis, the data on broiler mortality were transformed using arc sine (angular) transformation values to achieve a more normal distribution of the data (Zuidhof et al. 1995).

\section{Results}

\section{Growth performance}

Fermented feed and antibiotics both conveyed growth benefits. During the first 21 days, the body weight of FFH and FFL groups were improved than the NC group, but no significant differences were found in the body weight, FCR, ADG, and ADFI among the four groups ( $P>0.05$; Table 3$)$. No growth performance indices were changed significantly at the (22-42 day) period. The FFL and PC groups have been improved and significantly lower FCR over the NC group but trends towards lower in the FFH group than the NC group from 0-42 $(P<0.05)$. In the whole period ( 0 to 42 day) there is no significant difference, in any other growth performance indices. Mortality was also not significant for any time period but higher in the FFL group than NC and PC groups while no mortality was found in the FFH group during 0 to 21 day $(P>0.05$ Table 3), as due to treatment effects, lower mortality was observed during 21 to 42 day and complete period of 0 to 42 day.

\section{Slaughter Performance and Immune organs index}

All eviscerated ratios, breast and thigh muscles ratio, the relative rate of liver and fat were evaluated, all eviscerated ratio was higher in the PC group than the FFH group $(P<0.05)$. While on the other hand no differences were found for breast muscle, thigh muscle, liver, and abdominal fat rate parameters $(P>0.05$ Fig. 1).

Immune organs spleen, bursa, and thymus index were also measured. Thymus weight was higher in the $\mathrm{NC}$ group than FFL and FFH group $(P<0.05)$ whereas spleen and bursa were not different between groups (Fig. 1).

\section{Duodenum, jejunum, and ileum morphology}

The morphometric traits of the digestive tract of chicken in different groups are shown in Fig. 2. The morphology of the duodenum, jejunum, and ileum was significantly affected by diet supplementation with fermented feed, the intestine of all groups showed normal tissue architecture. The chicken fed 
with FFH had greater $(P<0.05)$ villus height for the duodenum than $\mathrm{PC}$, and higher VH/CR for the duodenum and ileum than PC and the FFL group. The FFL chickens had greater $(P<0.05)$ jejunal and ileal villus height than PC and NC groups respectively. The ileal VH/CD was higher $(P<0.05)$ in the FFL group than the other groups. However, jejunum VH/CD was higher $(P<0.05)$ in both FFL and FFH than in the PC group. Nevertheless, the duodenal and ilea crypts were significantly higher in PC and FFL respectively $(P<0.05)$, as compared to the $\mathrm{NC}$ group.

\section{Pro-inflammatory cytokine}

An increase in the gene expression of pro-inflammatory cytokine IL-1 $\beta$ and TLR4 was detected in the PC group than the NC group $(P<0.05$; Fig. 3A, B), whereas IL-10/ $\beta$ was higher in the FFL group than the NC group, although similar between PC, FFL, and FFH groups, while IL-4/ $\beta, I F N-\gamma \beta / \beta$, and IL-6/ $\beta$ were not different between groups.

\section{Analyses of microbiota composition}

The PCA analysis was applied to the data to illustrate the variation of the caecal microbiota between the groups. PC1 explained $33.06 \%$ of the variance and PC2 explained $26.87 \%$ (Fig. 4). The PCA revealed that the species of cecal samples among the groups were separated from the control NC group.

We observed that the dominant phyla in all four groups were Firmicutes, Bacteroides and Proteobacteria (Fig. 5A). The Bacilli, Bacterioda, Clostridia, and Negativicutes were the dominant class (Fig. 5B). The dominant family were Lactobacillae, Bacterideceae, and Rikenellacae (Fig. 5C). Whereas the Lactobacillus, Bacteroides, and Alisptes were the dominant genus (Fig. 5D). The dominant species included Bacteroidesphelibetes, Lactobacillus aviarus, Bacteriodes sp millerius (Fig. 5E). In different groups, no significant differences were found in the abundance of major phylum Firmicutes and Bacteroides, whereas FFH and PC groups have a lower abundance of Delsulfobacterota phylum compared with FFL and NC groups ( $P<0.05 ; \mathrm{Fig} .6)$. The class of Desulfovibriona was also decreased in the group treated with FFH and PC over FFL and NC groups ( $P<0.05$; Fig. 6$)$, while the abundance of class Negativicutes a gram-negative bacterium that belongs to phylum Firmicutes were considerably declined in FFH compared with other groups $(P<0.05$; Fig. 6$)$. The family having well-known probiotic bacteria the Lactobacillaceae were significantly increased in the FFH and FFL fermented feed groups compared with PC and NC groups $(P<0.05 ;$ Fig. 6$)$. Fermented feed groups FFH and FFL also increased the abundance of lactic acid producing genus Lactobacillus $(P<0.05 ; \mathrm{Fig}$. 6$)$. FFH increased the abundance of the Lactobacillus aviarus species followed by the FFL group compared with other groups $(P<0.05$; Fig. 6). Compared with the control NC group, the Lactobacillus aviarus species abundances were reduced in the PC group $(P<0.05$; Fig. 6$)$.

\section{Discussion}

Microbial fermentation has recently been developed as a cost-effective means to increase the nutritional value of broiler feed. The demand for fermented feed has risen as a consequence of the GIT health and 
growth performance benefits for the broiler industry's use of the fermenting process (Chiang et al. 2009; Skrede et al. 2003). Many reports have shown that fermentation of feedstuff with Lactobacillus can promote growth performance in chicken (Chiang et al. 2009; Skrede et al. 2003), although some studies have also reported that fermentation of feedstuff with Lactobacillus does not affect growth performance (Xu et al. 2012). In this study on the $21^{\text {st }}$ day, fermented feeds FFL and FFH groups showed improved weight gain as PC and, at the end of the experiment, the PC and FFL group has a significantly lower FCR. As demonstrated by Skrede et al. (2003) the positive effect of Lactobacillus fermentation on weight gain and feed conversion was found on wheat and barley in the diet. Improved feed conversion suggested a positive outcome of fermentation on nutrient digestibility and energy utilization, as confirmed in other studies (Skrede et al. 2001). The development of a well-balanced microflora given by fermented feed in the broiler diet may be responsible for improved growth efficiency. Proper fermented feed supplementation can create a favourable environment in the intestines for the colonisation of beneficial microflora, resulting in improved broilers' growth efficiency (Mohnl 2011).

The enhanced digestion and absorption that is obtained from fermentation is believed to lead to improved bird productivity (Drażbo et al. 2018). There is a powerful connection between increased villus height and the function of intestinal villi (Shamoto and Yamauchi 2000). In our study, the chicken fed with FFH had greater $(P<0.05)$ villus height and higher VH/CR for the duodenum and ileum. The FFL chickens had greater $(P<0.05)$ jejunal and ileal villus height and greater ileal $\mathrm{VH} / \mathrm{CD}(P$ $<0.05)$. However, jejunum VH/CD was higher $(P<0.05)$ in both FFL and FFH groups. Previous studies have shown that diets with fermented products have a beneficial effect on the structure and function of the small intestine in poultry (Hou et al. 2013; Liu et al. 2008) and as a result enhanced performance parameters (Drażbo et al. 2018; Jazi et al. 2018).

Fermented feed can improve histology by inhibiting excessive inflammation in the GIT, according to previous studies of Missotten et al. (2013), a recent studies link feeding the chicken lactic acid-fermented diets, which are usually higher in LAB bacteria, to increased resistance to infectious disease within those birds. Although the precise immunomodulatory activities of LAB in broilers are unknown, they may cause various subsets of immune cells to produce cytokines, which play important roles in the induction and regulation of immune responses. There is some evidence that some strains of Lactobacilli downregulated TLR4 expression (Bermudez-Brito et al. 2013). IL-10 is generally known to be an antiinflammatory cytokine, IL-10 production and regulatory T-cells are involved in the immune tolerance to intestinal microbiota (Cong et al. 2002; Kullberg et al. 2002). In our study IL-1 $\beta$, TLR4, and IL-6 expressions were decreased and IL10 expressions were increased with fermented feed FFL and FFH. This is in agreement with our finding that dietary fermented soybean meal in animals decreased IL-1 $\beta$ concentrations and increased IL-10 concentration than their corresponding controls (Zhang et al. 2018a). However, aside from better intestinal immunity, the poultry's immunity is normally increased in addition to a diet containing fermented ingredients, thus resulting in a higher weight of the bird's immune organs. To determine the immune system of animals, the relative weight of lymphoid organs is mostly used (SA et al. 2008). In the present study thymus index of the NC group was significantly higher than FFL and FFH 
group while no significant differences were found between different groups in spleen and bursa weight. Similarly, Tang et al. (2012) and Choi et al. (2014) found no significant differences in the relative weights of the spleen, thymus, and bursa of Fabricius in broilers after feeding with fermented feed. The above findings suggest that lymphoid compartments vary in their responses to the inclusion of fermented feed in chicken due to the different roles in the immune system. The bursa of Fabricius and spleen are sites of differentiation of B cells and T cells, respectively (Cooper et al. 1966). Variations in thymus weight could be associated with changes in the lymphoid organs' function. Hence higher thymus index in the NC group might be due to higher exposure of infections or a reduced capacity to maintaining production potential to meet the sanitation challenges (Fasina et al. 2006). It is important to realise that the lowest weight may not necessarily be linked with lower production of lymphoid cells; so this is essential that also consider other parameters of immunity status (Kabir et al. 2004; Makram et al. 2010).

The PCA revealed that the species of cecal samples among the groups were clearly separated from the NC control group. In contrast, despite no obvious differences in the microbiome in the antibiotic-group PC and fermented feed groups, based on PC2, indicating that the species of cecal samples might be influenced by the host feed, change in intestinal absorption, dysbiosis in ceca of the chicken broiler. The gut bacterial community and the abundance of bacterial metabolites are affected by diets, consequently, the gut microbiota composition influences nutrient digestibility (Fan et al. 2015; Fan et al. 2017). FFH and PC groups have a lower abundance of Delsulfobacterota phylum and class of Desulfovibriona compared with FFL and NC group ( $P<0.05$; Fig. 6 ). On the other hand Desulfobacterota phylum (formerly Deltaproteobacteria) are highly enriched with intestinal inflammation and injury in the gut of infected chickens (Oakley and Kogut 2016; Yitbarek et al. 2018), while the abundance of class Negativicutes a gram-negative bacterium belongs to phylum Firmicutes which were significantly decreased in FFH group compared with other groups. The members of the Negativicutes family have a gram-negative cell wall composition (Sutcliffe 2010). Lower abundance in FFH and PC groups may suggest that fermentation effectively reduced infection and harmful bacteria. Stimulatingly, lactic acid produced by Lactobacillus is necessary for antimicrobial activities to suppress the development and growth of virulence factors of Gram-negative bacteria (Zhang et al. 2018b). The mixture of $P$. acidilactici and L. fermentum may drop the Anaerovibrio by promoting lactic acid production, which filters through the gram-negative bacterial outer membrane (Alakomi et al. 2000). Lactobacillus aviarus was significantly increased in the FFH and FFL fermented feed groups compared with PC and NC groups $(P<0.05$; Fig. 6). Lactobacillus $\mathrm{sp}$. is well known for its beneficial effect on humans and animals, so a high level of Lactobacillus sp. is associated with chicken health (Coeuret et al. 2004). The previous research has also shown that feeding with Lactobacillus strain significantly increases the diversity of Lactobacilli in the ileum and cecum of broilers (Chim-anage et al. 2008; Nakphaichit et al. 2011). These changes in cecal microbiota towards positive increase beneficial bacteria in FFL and FFH.

\section{Conclusion And Perspective}

This study demonstrated that fermented feed exhibits dose-dependent beneficial influences on gut microbiota and morphology and immune functions birds. Although the growth promoting effect, such as 
feed efficiency, of fermented feed was not as good as that of antibiotics, it was significantly better than antibiotics in reducing the chickens' mortality. However, limited data is available, so future studies must be consistent in their study approaches, as well as maintaining awareness of how feed fermentation ingredients affect the broiler population's microbiota.

\section{Abbreviations}

\begin{tabular}{ll} 
NC: & Negative control basal diet \\
\hline PC: & Positive control basal diet +antibiotic \\
\hline FFL: & Basal diet + Fermented feed low dose \\
\hline FFH: & Basal diet + Fermented feed high dose \\
\hline FCR: & Feed conversion ratio \\
\hline ADG: & Average daily gain \\
\hline ADFI: & Average daily feed intake \\
\hline BW: & Body weight \\
\hline IL-1B: & Interleukin 1 beta \\
\hline IL-6: & Interleukin 6 \\
\hline IL-10: & Interleukin 10 \\
\hline IL-4: & Interleukin 4 \\
\hline IFNY: & Interferon gamma \\
\hline TLR4: & Toll-like receptor 4 \\
\hline qRT-PCR: & Quantitative real-time PCR \\
\hline VH: & Villus height \\
\hline CD: & Crypt depth \\
\hline AGPs: & Antibiotic growth promoters \\
\hline
\end{tabular}

\section{Declarations}

\section{Availability of data and materials}

The datasets generated and/or analysed during this study are available from the corresponding author on reasonable request.

\section{Funding}


This work was supported by Guangdong key research and development program (2019B020218001) and the local innovative and research teams project of Guangdong province (2019BT02N630).

\section{Author contributions}

Wentong Peng, Mir Zulqarnain Talpur, Gang Shu, and Haijun Zhang contributed to the design and implementation of the research, to the analysis of the results also helped in the elaboration of the project and its execution and financing. Yuxian Zeng, and Peipei Xie Jincheng Li, Songbo Wang, Lina Wang, and Xiaotong Zhu participated in the execution of the experiment and collection of samples and data. Ping Gao and Qingyan Jiang did the laboratory analysis. All authors discussed the results and contributed to the final manuscript.

\section{Ethics declarations}

\section{Ethics approval}

The animal trial was approved by the Animal Ethics Committee at The South China Agricultural University under approval number: ACE-CAAS-20201211.

\section{Consent for publication}

Not applicable.

\section{Competing interests}

The authors declare that they have no competing no financial competing interests.

\section{References}

Aktas B, De Wolfe TJ, Tandee K, Safdar N, Darien BJ, Steele JL (2015) The effect of Lactobacillus casei $32 \mathrm{G}$ on the mouse cecum microbiota and innate immune response is dose and time dependent. PloS one 10(12):e0145784

Alakomi H-L, Skyttä E, Saarela M, Mattila-Sandholm T, Latva-Kala K, Helander I (2000) Lactic acid permeabilizes gram-negative bacteria by disrupting the outer membrane. Appl Microbiol Biotechnol 66(5):2001-2005

Alshelmani M, Loh T, Foo H, Sazili A, Lau W (2016) Effect of feeding different levels of palm kernel cake fermented by Paenibacillus polymyxa ATCC 842 on nutrient digestibility, intestinal morphology, and gut microflora in broiler chickens. Anim Feed Sci Technol 216:216-224

Bermudez-Brito M, Muñoz-Quezada S, Gomez-Llorente C, Matencio E, Bernal MJ, Romero F, Gil A (2013) Cell-free culture supernatant of Bifidobacterium breve CNCM I-4035 decreases pro-inflammatory 
cytokines in human dendritic cells challenged with Salmonella typhi through TLR activation. PLoS One 8(3):e59370

Chiang G, Lu W, Piao X, Hu J, Gong L, Thacker P (2009) Effects of feeding solid-state fermented rapeseed meal on performance, nutrient digestibility, intestinal ecology and intestinal morphology of broiler chickens. Asian-australas J Anim Sci 23(2):263-271

Chim-anage P, Hirunvong V, Sirirote P, Malaphan W, Yongsmith B, Isariyodom S, Tirawattanawanich C, Chitanont W, Talsook P (2008) Effect of feed supplementation of lactic acid bacteria on microbial changes in broiler intestine. Agric Nat Resour 42(5):269-276

Choi Y, Lee S, Oh J (2014) Effects of dietary fermented seaweed and seaweed fusiforme on growth performance, carcass parameters and immunoglobulin concentration in broiler chicks. Asian-australas $\mathrm{J}$ Anim Sci 27(6):862

Coeuret V, Gueguen M, Vernoux JP (2004) Numbers and strains of lactobacilli in some probiotic products. Int J Food Microbiol 97(2):147-156

Cong Y, Weaver CT, Lazenby A, Elson CO (2002) Bacterial-reactive T regulatory cells inhibit pathogenic immune responses to the enteric flora. J Immunol 169(11):6112-6119

Cooper MD, Peterson RD, South MA, Good RA (1966) The functions of the thymus system and the bursa system in the chicken. J Exp Med 123(1):75-102

Dewar ML, Arnould JP, Dann P, Trathan P, Groscolas R, Smith S (2013) Interspecific variations in the gastrointestinal microbiota in penguins. Microbiologyopen 2(1):195-204

Drażbo A, Ognik K, Zaworska A, Ferenc K, Jankowski J (2018) The effect of raw and fermented rapeseed cake on the metabolic parameters, immune status, and intestinal morphology of turkeys. Poult Sci 97(11):3910-3920

Fan P, Li L, Rezaei A, Eslamfam S, Che D, Ma X (2015) Metabolites of dietary protein and peptides by intestinal microbes and their impacts on gut. Curr Protein Pept Sci 16(7):646-654

Fan P, Liu P, Song P, Chen X, Ma X (2017) Moderate dietary protein restriction alters the composition of gut microbiota and improves ileal barrier function in adult pig model. Sci Rep 7(1):1-12

Fasina Y, Classen H, Garlich J, Black B, Ferket P, Uni Z, Olkowski A (2006) Response of turkey poults to soybean lectin levels typically encountered in commercial diets. 2. Effect on intestinal development and lymphoid organs. Poult Sci 85(5):870-877

Gao M, Cieślak A, Kierończyk B, Huang H, Yanza YR, Zaworska-Zakrzewska A, Józefiak D, SzumacherStrabel M (2020) Effects of Raw and Fermented Rapeseed Cake on Growth Performance, Methane Production, and Breast Meat Fatty Acid Composition in Broiler Chickens. Animals 10(12):2250 
Hou Y, Wang L, Yi D, Ding B, Yang Z, Li J, Chen X, Qiu Y, Wu G (2013) N-acetylcysteine reduces inflammation in the small intestine by regulating redox, EGF and TLR4 signaling. Amino Acids 45(3):513522

Ivory K, Chambers S, Pin C, Prieto E, Arques J, Nicoletti C (2008) Oral delivery of Lactobacillus casei Shirota modifies allergen-induced immune responses in allergic rhinitis. Clin Exp Allergy 38(8):1282-1289

Jazi V, Ashayerizadeh A, Toghyani M, Shabani A, Tellez G (2018) Fermented soybean meal exhibits probiotic properties when included in Japanese quail diet in replacement of soybean meal. Poult Sci 97(6):2113-2122

Kabir SL, Rahman M, Rahman M, Rahman M, Ahmed S (2004) The dynamics of probiotics on growth performance and immune response in broilers. Int J Poult Sci 3(5):361-364

Kullberg MC, Jankovic D, Gorelick PL, Caspar P, Letterio JJ, Cheever AW, Sher A (2002) Bacteria-triggered CD4+ T regulatory cells suppress Helicobacter hepaticus-induced colitis. J Exp Med 196(4):505-515

Li C-I, Wang J, Zhang H-j, Wu S-g, Hui Q-r, Yang C-b, Fang R-j, Qi G-h (2019) Intestinal morphologic and microbiota responses to dietary Bacillus spp. in a broiler chicken model. Front Physiol 9:1968

Liu T, She R, Wang K, Bao H, Zhang Y, Luo D, Hu Y, Ding Y, Wang D, Peng K (2008) Effects of rabbit sacculus rotundus antimicrobial peptides on the intestinal mucosal immunity in chickens. Poult Sci 87(2):250-254

Loh T, Law F, Foo H, Goh Y, Zulkifli I (2007) Effects of feeding a fermented product on egg production, faecal microflora and faecal pH in laying hens. J Anim Feed Sci 16(3):452

Makram A, Galal A, Fathi M, El-Attar A (2010) Carcass characteristics and immunocompetence parameters of four commercial broiler strain chickens under summer season of Egypt. Int J Poult Sci 9(2):171-176

Missotten J, Michiels J, Dierick N, Ovyn A, Akbarian A, De Smet S (2013) Effect of fermented moist feed on performance, gut bacteria and gut histo-morphology in broilers. Br Poult Sci 54(5):627-634

Mohnl M (2011) Poultry production: how probiotics can play a role. Feed International 32(5):16-17

Nakphaichit M, Thanomwongwattana S, Phraephaisarn C, Sakamoto N, Keawsompong S, Nakayama J, Nitisinprasert S (2011) The effect of including Lactobacillus reuteri KUB-AC5 during post-hatch feeding on the growth and ileum microbiota of broiler chickens. Poult Sci 90(12):2753-2765

NRC U (1994) Nutrient requirements of poultry. National Academy Press Washington, DC

Oakley BB, Kogut MH (2016) Spatial and temporal changes in the broiler chicken cecal and fecal microbiomes and correlations of bacterial taxa with cytokine gene expression. Front Vet Sci 3:11 
SA A-F, El-Sanhoury M, El-Mednay N, Abdel-Azeem F (2008) Thyroid activity, some blood constituents, organs morphology and performance of broiler chicks fed supplemental organic acids. Int J Poult Sci $7(3): 215-222$

Shamoto K, Yamauchi K (2000) Recovery responses of chick intestinal villus morphology to different refeeding procedures. Poult Sci 79(5):718-723

Singhania RR, Patel AK, Thomas L, Pandey A (2017) Solid-state fermentation. Industrial Biotechnology: Products and Processes 4:187-204

Skrede G, Herstad O, Sahlstrøm S, Holck A, Slinde E, Skrede A (2003) Effects of lactic acid fermentation on wheat and barley carbohydrate composition and production performance in the chicken. Anim Feed Sci Technol 105(1-4):135-148

Skrede G, Sahlstrøm S, Skrede A, Holck A, Slinde E (2001) Lactic acid fermentation of wheat and barley whole meal flour modifies carbohydrate composition and increases digestibility in mink (Mustela vison). Anim Feed Sci Technol 90:199-212

Sopková D, Hertelyová Z, Andrejčáková Z, Vlčková R, Gancarčíková S, Petrilla V, Ondrašovičová S, Krešáková $L$ (2017) The application of probiotics and flaxseed promotes metabolism of n-3 polyunsaturated fatty acids in pigs. J Appl Anim Res 45(1):93-98

Stanton TB (2013) A call for antibiotic alternatives research. Trends Microbiol 21(3):111-113

Sutcliffe IC (2010) A phylum level perspective on bacterial cell envelope architecture. Trends Microbiol 18(10):464-470

Tang J, Sun H, Yao X, Wu Y, Wang X, Feng J (2012) Effects of replacement of soybean meal by fermented cottonseed meal on growth performance, serum biochemical parameters and immune function of yellowfeathered broilers. Asian-australas J Anim Sci 25(3):393

Wang H, Wang B, Zhao Q, Zhao Y, Fu C, Feng X, Wang N, Su M, Tang C, Jiang F (2015) Antibiotic body burden of Chinese school children: a multisite biomonitoring-based study. Environ Sci Technol 49(8):5070-5079

Wang Y, Liu X, Wang H, Li D, Piao X, Lu W (2014) Optimization of processing conditions for solid-state fermented soybean meal and its effects on growth performance and nutrient digestibility of weanling pigs. Livest Sci 170:91-99

Xia J, Wishart DS (2011) Web-based inference of biological patterns, functions and pathways from metabolomic data using MetaboAnalyst. Nat Protoc 6(6):743-760

Xu F, Zeng X, Ding X (2012) Effects of replacing soybean meal with fermented rapeseed meal on performance, serum biochemical variables and intestinal morphology of broilers. Asian-australas J Anim 
Sci 25(12):1734

Yang Y, lji P, Choct M (2009) Dietary modulation of gut microflora in broiler chickens: a review of the role of six kinds of alternatives to in-feed antibiotics. Worlds Poult Sci J 65(1):97-114

Yeh RH, Hsieh CW, Chen KL (2018) Screening lactic acid bacteria to manufacture two-stage fermented feed and pelleting to investigate the feeding effect on broilers. Poult Sci 97(1):236-246

Yitbarek A, Weese JS, Alkie TN, Parkinson J, Sharif S (2018) Influenza A virus subtype H9N2 infection disrupts the composition of intestinal microbiota of chickens. FEMS Microbiol Ecol 94(1):fix165

Zhang J, Zhu J, Sun J, Li Y, Wang P, Jiang R, Rahman MRT (2016a) Effect of fermented feed on intestinal morphology, immune status, carcass and growth performance of Emei Black chickens. FASEB J 30:Ib240lb240

Zhang Y, Shi C, Wang C, Lu Z, Wang F, Feng J, Wang Y (2018a) Effect of soybean meal fermented with Bacillus subtilis BS12 on growth performance and small intestinal immune status of piglets. Food Agr Immunol 29(1):133-146

Zhang Z, Lv J, Pan L, Zhang Y (2018b) Roles and applications of probiotic Lactobacillus strains. Appl Microbiol Biotechnol 102(19):8135-8143

\section{Tables}

Table 1 Test diet formula and nutritional level 


\begin{tabular}{|c|c|c|}
\hline Items & Starter diet & Grower diet \\
\hline Ingredient $\%$ & $0 \sim 21 \mathrm{~d}$ & $21 \sim 42 \mathrm{~d}$ \\
\hline Corn & 56.59 & 59.96 \\
\hline Soybean meal & 25.95 & 20 \\
\hline Cotton meal & 4.5 & 4.42 \\
\hline Wheat meal & 4 & 5 \\
\hline Wheat middlings & 2 & 2 \\
\hline Oil & 2.49 & 4.5 \\
\hline Calcium hydrogen phosphate & 1.82 & 1.58 \\
\hline Mountain flour & 1.35 & 1.27 \\
\hline Salt & 0.35 & 0.35 \\
\hline Lysine & 0.35 & 0.35 \\
\hline Methionine & 0.23 & 0.21 \\
\hline Threonine & 0.05 & 0.04 \\
\hline Premix of trace elements ${ }^{\square}$ & 0.2 & 0.2 \\
\hline Vitamin premix $x^{\square}$ & 0.02 & 0.02 \\
\hline Choline chloride & 0.1 & 0.1 \\
\hline Total & 100 & 100 \\
\hline \multicolumn{3}{|l|}{ Nutrition level ${ }^{\square}$} \\
\hline Metabolizable energy $(\mathrm{kcal} / \mathrm{kg})$ & 2980 & 3160 \\
\hline Crude protein (\%) & 21.95 & 19.95 \\
\hline Calcium (\%) & 1 & 0.9 \\
\hline Available phosphorus (\%) & 0.45 & 0.4 \\
\hline Lysine (\%) & 1.30 & 1.15 \\
\hline Methionine (\%) & 0.58 & 0.54 \\
\hline Methionine+Cystine $\% \rrbracket$ & 0.94 & 0.87 \\
\hline Threonine (\%) & 0.84 & 0.75 \\
\hline Tryptophan (\%) & 0.23 & 0.2 \\
\hline
\end{tabular}


Note: ${ }^{\square}$ Premix of trace elements (provides milligrams per kilogram of feed): $\mathrm{Cu} 8, \mathrm{Zn} \mathrm{75,} \mathrm{Fe} \mathrm{80,} \mathrm{Mn} \mathrm{100,}$ Se $0.15,10.35$

Vitamin premix (provided per kilogram of feed): Vitamin A 12500 IU, Vitamin D3 2500 IU; The following are mg: Vitamin E 18.75, Vitamin K3 2.65, Vitamin B12, Vitamin B2 6, Vitamin B12 0.025, Biotin 0.0325, Folic acid 1.25 , pantothenic acid 12 , niacin 50

${ }^{\square}$ the results are calculated values

Table 2 Real-time quantitative RT-PCR probes and primers

\begin{tabular}{|c|c|c|}
\hline Gene & Sequence type-Probe/primer sequence & Accession number \\
\hline IL-1 $\beta$ & $\begin{array}{l}\text { forward 5'-TTCATTACCGTCCCGTTG-3' } \\
\text { reverse 5'-GCTTTTATTTCTCCAGTCACA-3' }\end{array}$ & 『NM_204524.1区 \\
\hline IL-6 & 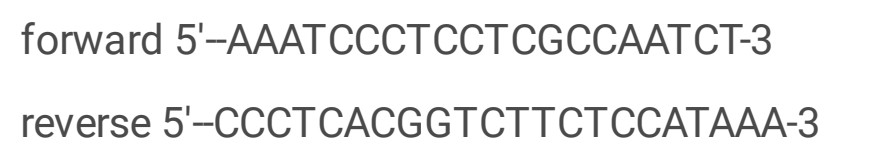 & 『NM_204628.1区 \\
\hline IL-10 & $\begin{array}{l}\text { forward 5'-CGCTGTCACCGCTTCTTCA-3 } \\
\text { reverse 5'-TCССGTTСТСАTССАТСТTСTC-3 }\end{array}$ & 『NM_001004414.2区 \\
\hline IL-4 & $\begin{array}{l}\text { forward 5'-GTGCCCACGCTGTGCTTAC -3 } \\
\text { reverse 5'-AGGAAACCTCTCCCTGGATGTC-3 }\end{array}$ & QNM_001007079.1区 \\
\hline IFNy & $\begin{array}{l}\text { forward 5'-GCCCTTCCTGTAACCAGATG-3 } \\
\text { reverse 5'-ACACGACAGCCAAGTCAACG-3 }\end{array}$ & 『NM_205149.1区 \\
\hline TLR4 & $\begin{array}{l}\text { forward 5'-TTTCCAAGCACCAGATAGCAACA-3 } \\
\text { reverse 5'-TTCCAGCACAAGCCCTGAAATTA-3 }\end{array}$ & 『NM_001030693.1区 \\
\hline
\end{tabular}

Interleukin 1 beta, Toll-like receptor 4, Interleukin 6, Interleukin 10, Interleukin 4, Interferon gamma.

Table 3 Effect of fermented feed supplementation and antibiotic on growth performance in broiler chicks ${ }^{1}$ 


\begin{tabular}{llllll} 
Items $^{2}$ & NC & PC & FFL & FFH & $P$-value \\
\hline $1-21$ day & & & & & \\
\hline ADG, g & $40.53 \pm 0.70$ & $41.69 \pm 2.43$ & $41.48 \pm 2.51$ & $42.87 \pm 1.37$ & 0.32 \\
\hline ADFl, g & $48.31 \pm 2.60$ & $48.42 \pm 2.44$ & $48.85 \pm 1.88$ & $50.49 \pm 1.53$ & 0.38 \\
\hline FCR (g:g) & $1.19 \pm 0.05$ & $1.16 \pm 0.01$ & $1.179 \pm 0.03$ & $1.178 \pm 0.30$ & 0.62 \\
\hline Mortality & $0.19 \pm 1.19$ & $1.19 \pm 1.19$ & $3.33 \pm 2.04$ & 0 & 0.16 \\
\hline 21 d BW $^{3}$ & $904.90 \pm 19.94^{\mathrm{b}}$ & $931.66 \pm 53.69^{\mathrm{ab}}$ & $971.02 \pm 36.42^{\mathrm{a}}$ & $972.16 \pm 24.75^{\mathrm{a}}$ & 0.02
\end{tabular}

\section{$22-42 d$}

\begin{tabular}{llllll}
\hline ADG, g & $76.90 \pm 15.98$ & $71.01 \pm 6.61$ & $77.28 \pm 16.94$ & $80.55 \pm 9.97$ & 0.71 \\
\hline ADFl, g & $140.42 \pm 23.92$ & $131.68 \pm 13.59$ & $142.60 \pm 24.86$ & $148.85 \pm 13.33$ & 0.59 \\
\hline FCR $(\mathrm{g}: \mathrm{g})$ & $1.840 \pm 0.090$ & $1.853 \pm 0.020$ & $1.863 \pm 0.110$ & $1.855 \pm 0.089$ & 0.98 \\
\hline Mortality $^{3}$ & $8.44 \pm 2.57$ & $4.87 \pm 1.72$ & $1.82 \pm 1.82$ & $3.33 \pm 2.04$ & 0.34 \\
\hline 42 d BW $^{2}$ & $2891.27 \pm 376.0$ & $2762.44 \pm 209.0$ & $2863.69 \pm 435.3$ & $3058.68 \pm 203.9$ & 0.55
\end{tabular}

$42 d$

\begin{tabular}{llllll}
\hline ADG, g & $58.04 \pm 7.87$ & $56.61 \pm 6.06$ & $58.46 \pm 8.95$ & $60.93 \pm 4.79$ & 0.81 \\
\hline ADFI, g & $92.70 \pm 11.58$ & $88.64 \pm 8.46$ & $93.39 \pm 12.61$ & $97.69 \pm 6.16$ & 0.57 \\
\hline FCR $(\mathrm{g}: \mathrm{g})$ & $1.612 \pm 0.013^{\mathrm{b}}$ & $1.567 \pm 0.022^{\mathrm{a}}$ & $1.590 \pm 0.050^{\mathrm{a}}$ & $1.605 \pm 0.042^{\mathrm{ab}}$ & 0.05 \\
\hline Mortality $^{3}$ & $9.63 \pm 2.88$ & $6.06 \pm 1.57$ & $5.15 \pm 3.47$ & $3.33 \pm 2.04$ & 0.63
\end{tabular}

$1 \mathrm{n}=6$ replicates per treatment.

2Negative control (NC), Positive control (Antibiotic) (PC), Fermented feed (low dose) (FFL), Fermented feed (high dose) (FFH).

3Values transformed by arc sine (angular) transformation.

$A D G$, average daily gain; $A D F I$, average daily feed intake; FCR (feed: gain = g: g), feed conversion ratio; BW, body weight.

Note『Values with different superscripts in the same row differ $(P<0.05)$. 
Figures
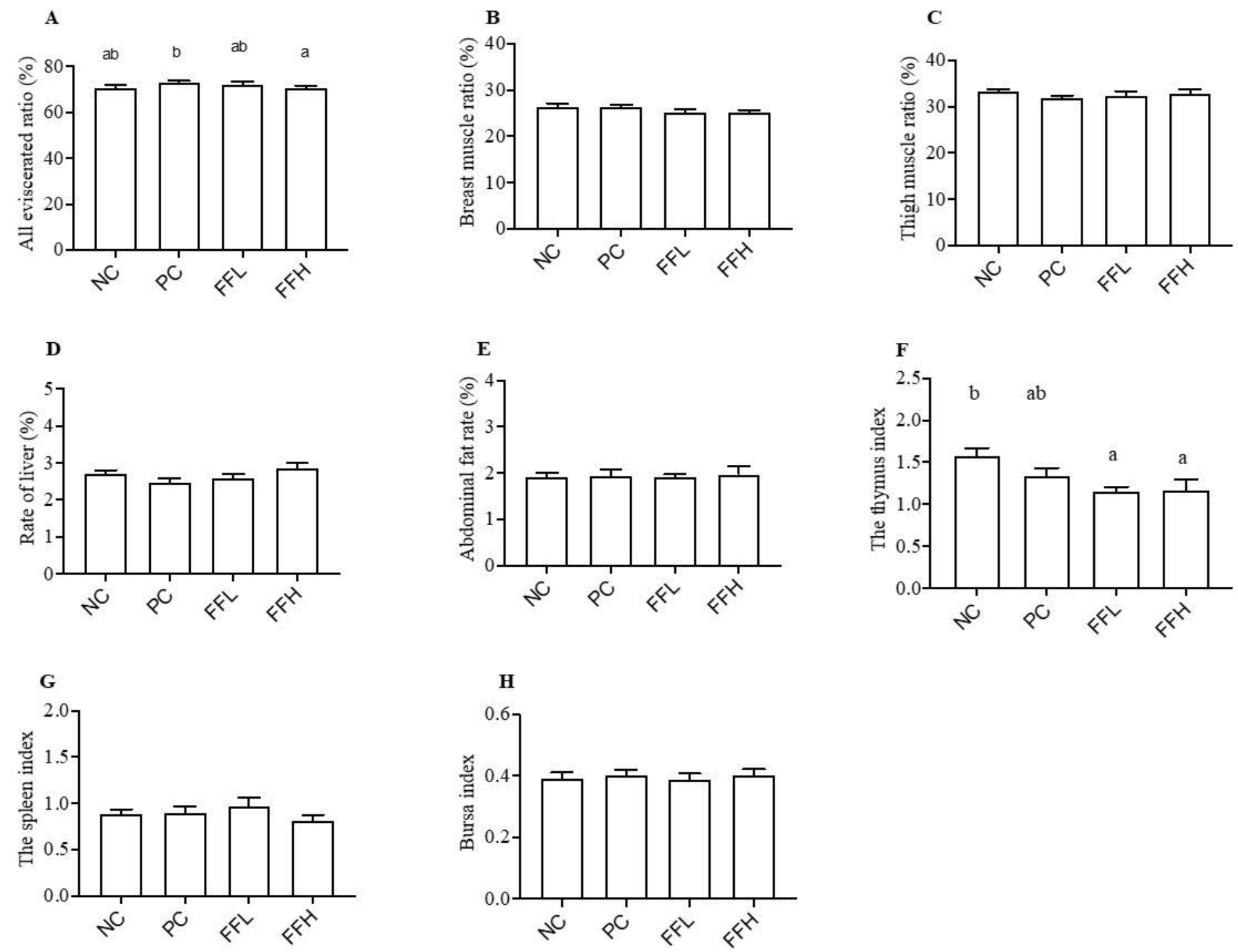

Figure 1

Effect of antibiotic and fermented feed on eviscerated yield, component parts, meat ratios, and immune organs in broiler chicken. Negative control (NC), Positive control (Antibiotic) (PC), Fermented feed (low dose) (FFL), Fermented feed (high dose) (FFH). Values with different superscripts in the same row differ $(P<0.05)$. Different color bar plots showing different groups. $n=6$ replicates per treatment. 

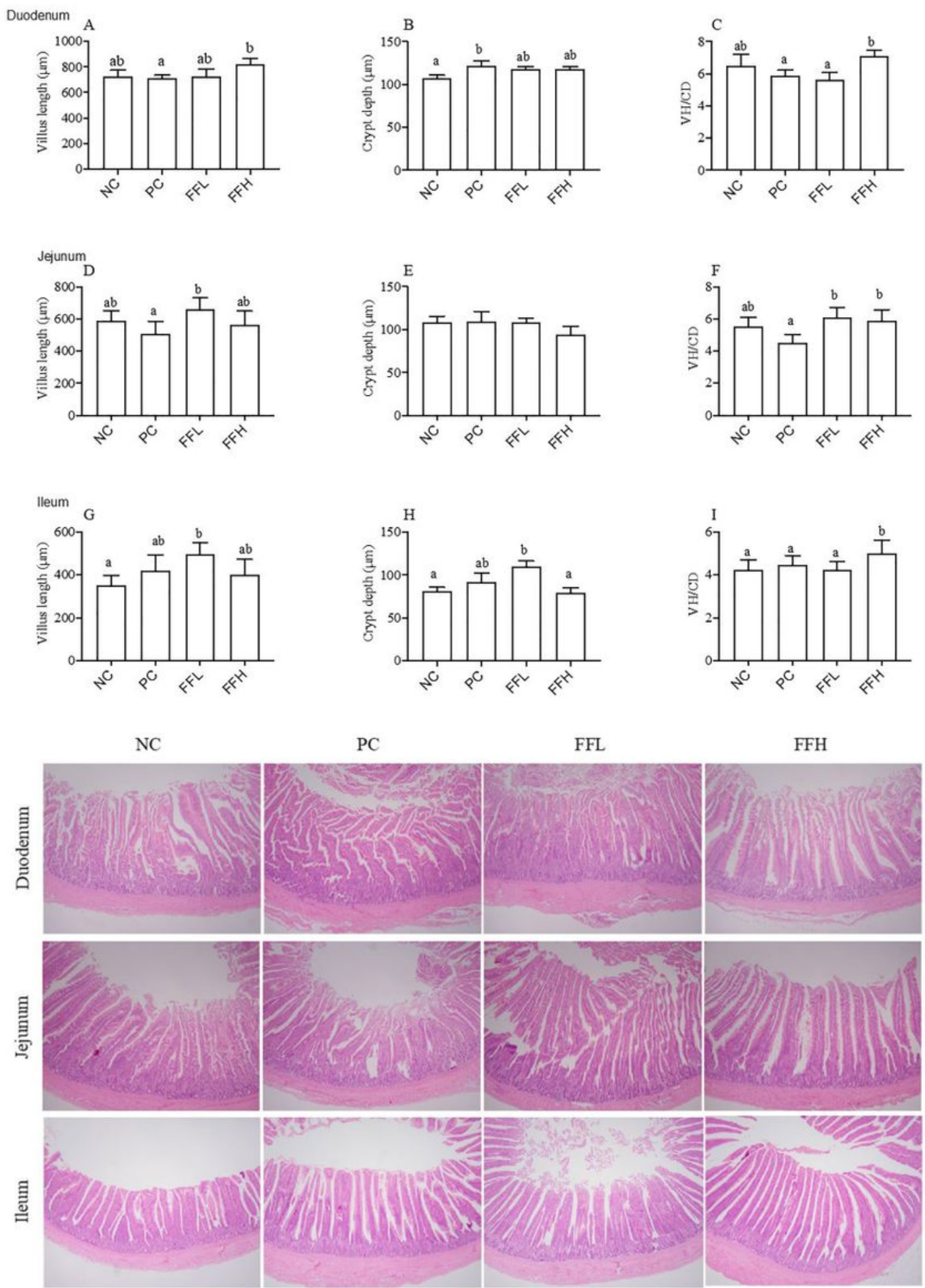

\section{Figure 2}

a. Effect of antibiotic and fermented feed on duodenum, jejunum, and ileum in broiler chicken. Negative control (NC), Positive control (Antibiotic) (PC), Fermented feed (low dose) (FFL), Fermented feed (high dose) $(F F H)$. Values with different superscripts in the same row differ $(P<0.05)$. Different color bar plots showing different groups. $\mathrm{n}=6$ replicates per treatment. b. Effect of antibiotic and fermented feed on small intestine's (duodenum, jejunum, and ileum ) morphology in broiler chicken. Negative control (NC), 
Positive control (Antibiotic) (PC), Fermented feed (low dose) (FFL), Fermented feed (high dose) (FFH). The gross and microscopic views of different parts of chickens' intestine in treatment groups and control group. The intestine parts duodenum, jejunum, and ileum sections were used. Histology was assessed for intestine sections embedded in paraffin - sections stained with hematoxylin and eosin. $n=6$ replicates per treatment.
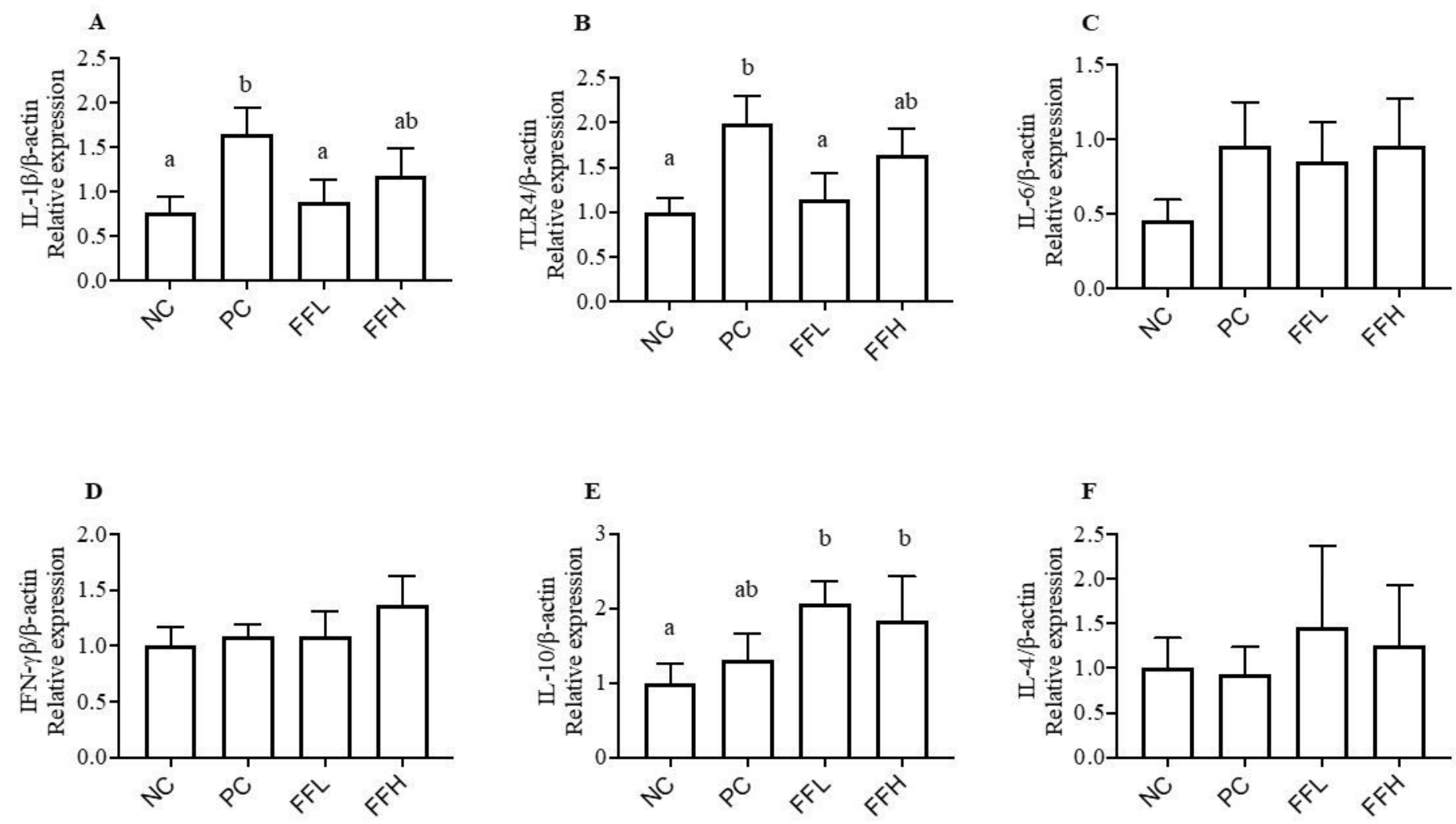

Figure 3

Effect of antibiotic and fermented feed on the relative gene expression of inflammatory cytokines of broiler chickens. Negative control (NC), Positive control (Antibiotic) (PC), Fermented feed (low dose) (FFL), Fermented feed (high dose) (FFH). Values with different superscripts in the same row differ $(\mathrm{P}<0.05)$. Interleukin 1 beta, Toll-like receptor 4, Interleukin 6, Interleukin 10, Interleukin 4, Interferon gamma. n= 6 replicates per treatment. 


\section{PCA on species level}

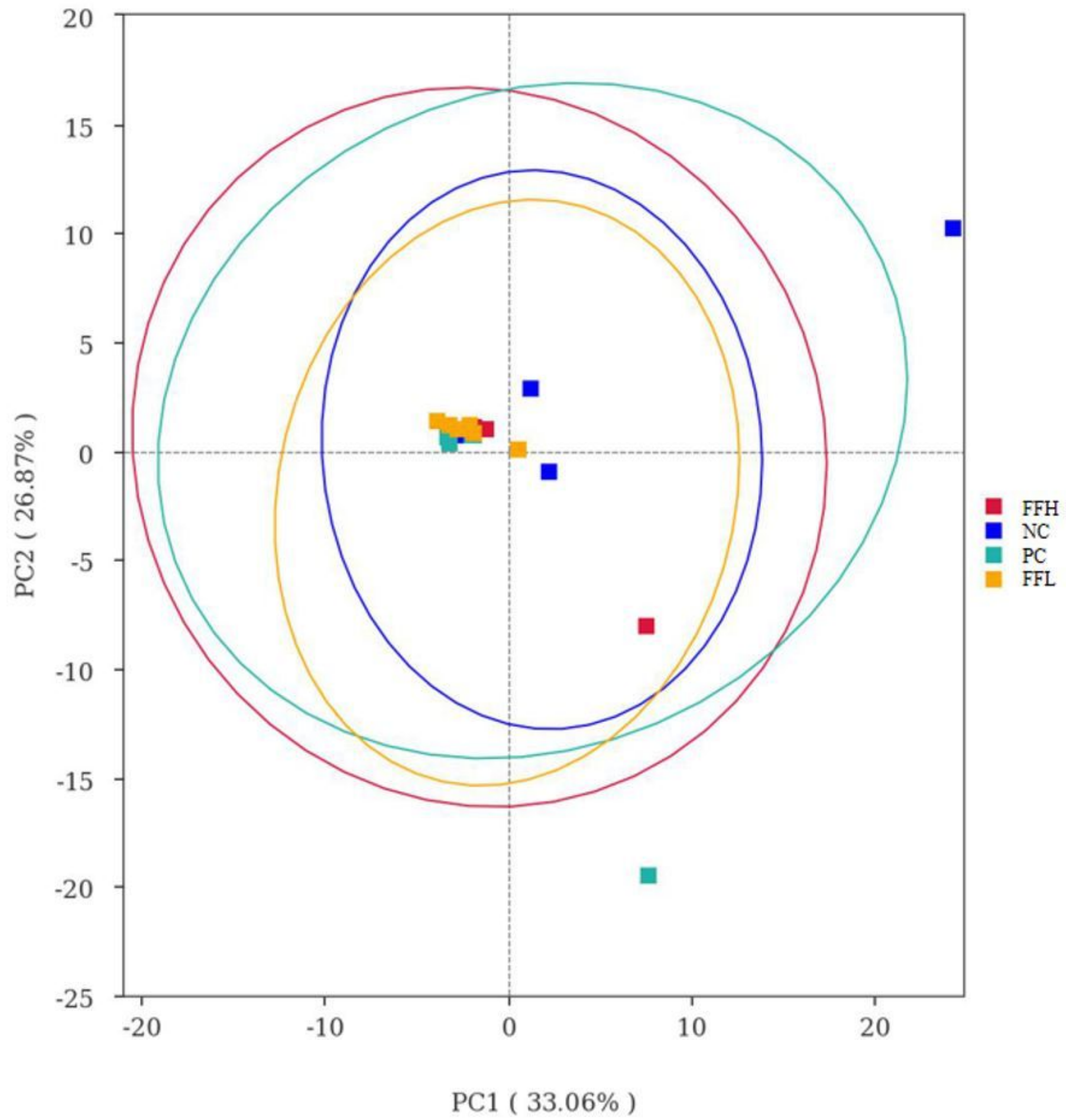

Figure 4

PCA on species level. Negative control (NC), Positive control (Antibiotic) (PC), Fermented feed (low dose) (FFL), Fermented feed (high dose) (FFH). 
A. phylum

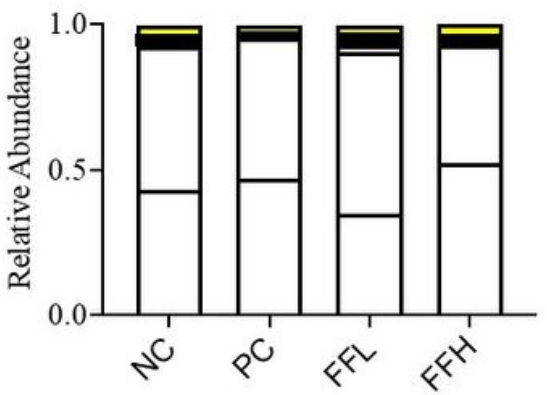

C. order

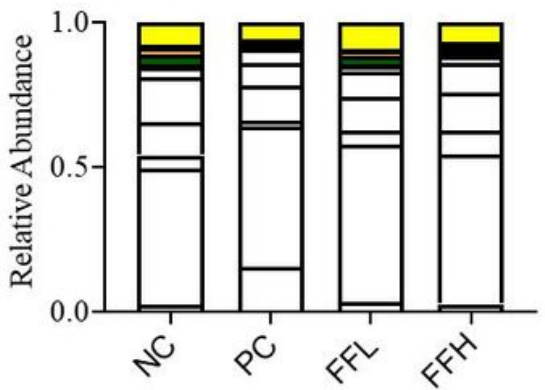

E. genus

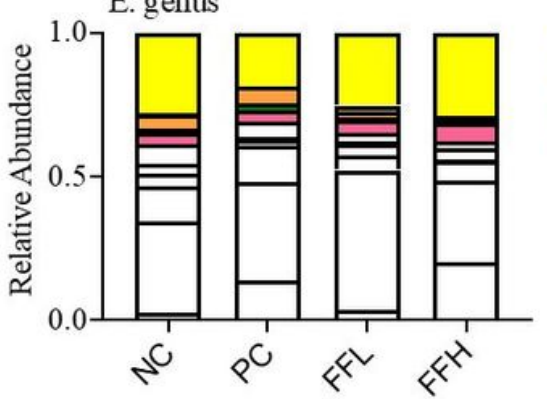

B. class
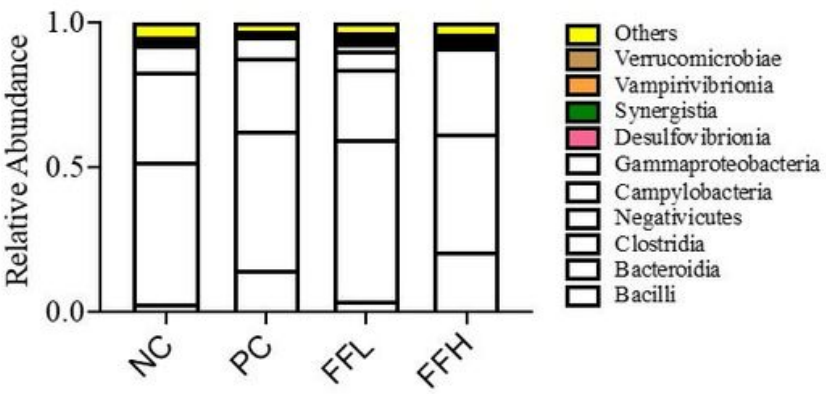

D. family

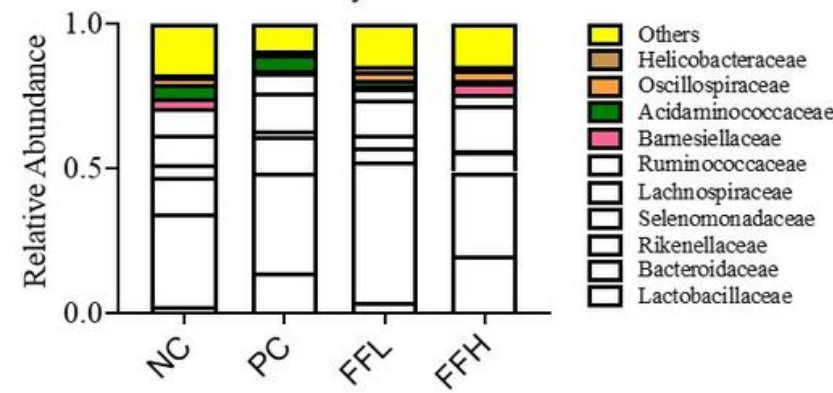

F. species

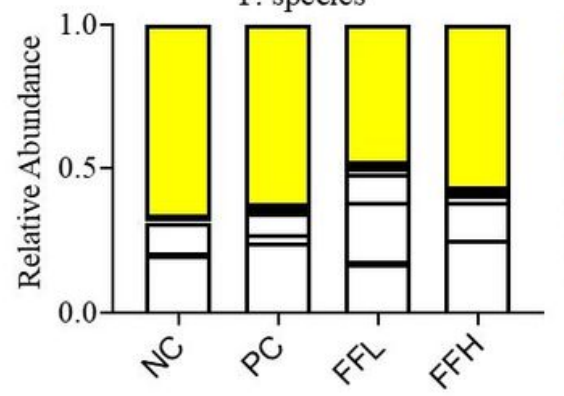

thers

Desulfovibrio_piger Lactobacillus oris Bacteroides uniformis Parasutterella_secunda Helicobretor pullorm Helicobacter_pullorum Bacteroides_salanitronis Bacteroides barnesiae Bacteroides_Sp_Marseille-P3166 Lactobacillus aviarius Bacteroides plebeius

Figure 5

Effect of antibiotic and fermented feed on the Relative Abundance of broiler chickens. Negative control (NC), Positive control (Antibiotic) (PC), Fermented feed (low dose) (FFL), Fermented feed (high dose) (FFH). The microbiome compositions in cecum at phylum, class, family genus, and species-level composition of the caecal microbiome of chicken. A color-coded bar plot shows the average bacterial phylum, class, family, genus, and species distribution in different treatment groups and control groups. Each bar chart represents the relative abundance of each group. Each color represents a specific bacteria phylum (A) a specific bacteria class (B) a specific bacteria order (C) a specific bacteria family (D) a specific bacteria genus $(\mathrm{E})$ and a specific bacteria species $(\mathrm{F})$ 
A. H-test bar plot on phylum level

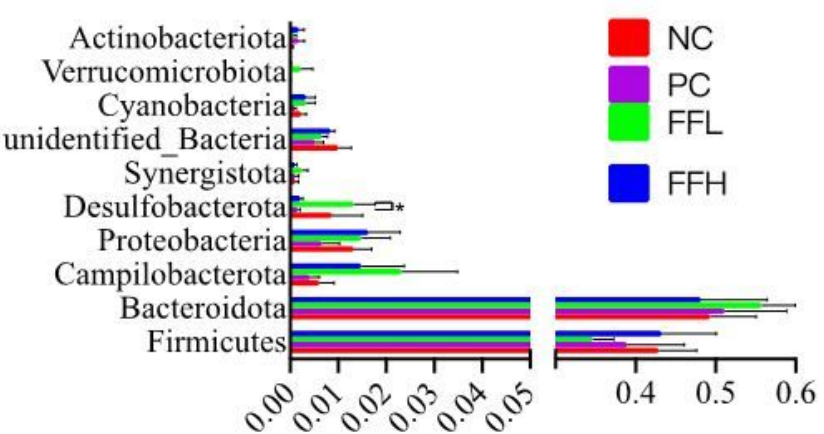

C. H-test bar plot on order level

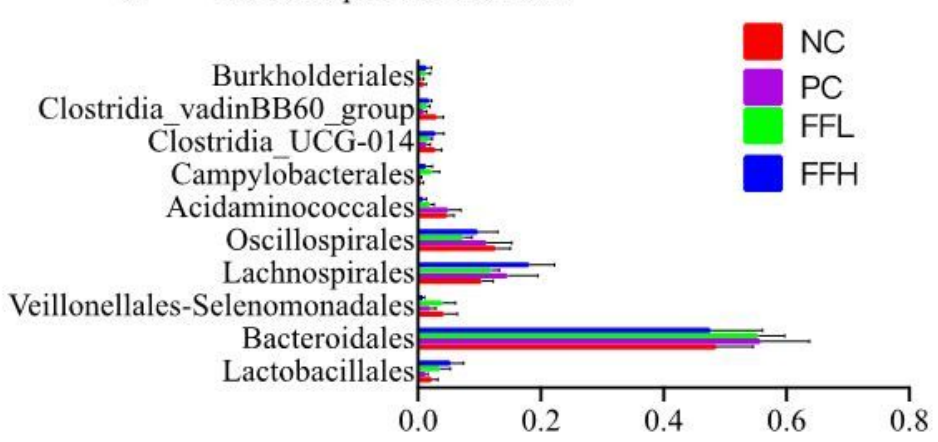

E. H-test bar plot on genus level

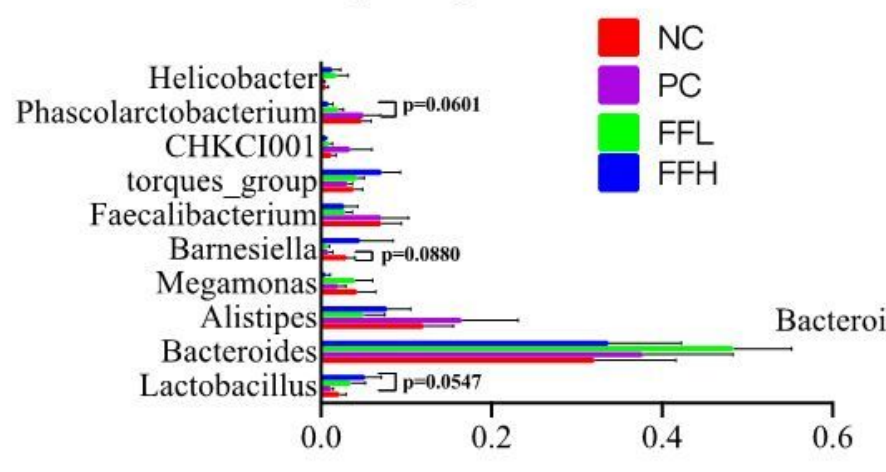

B. H-test bar plot on class level

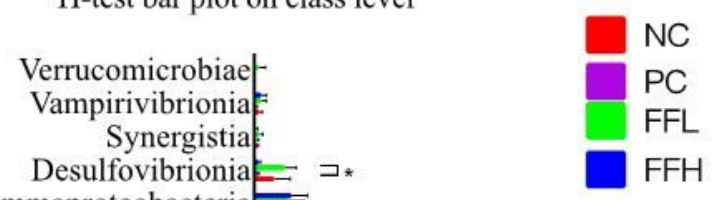

Campylobacteria

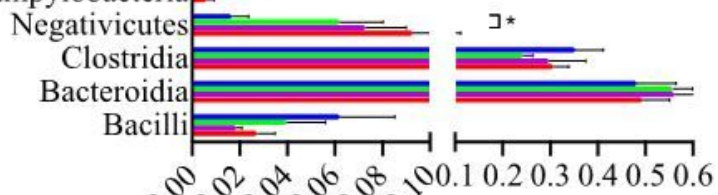

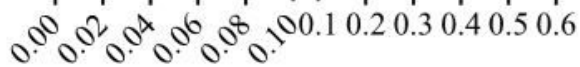

D. H-test bar plot on family level

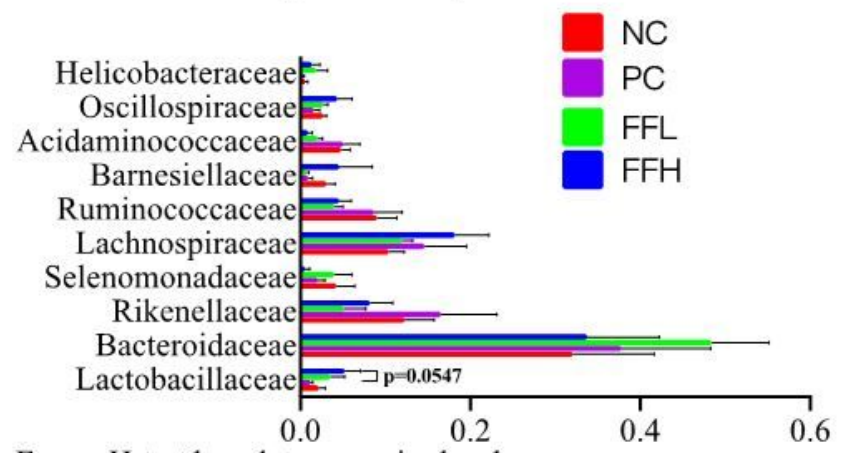

F. H-test bar plot on species level

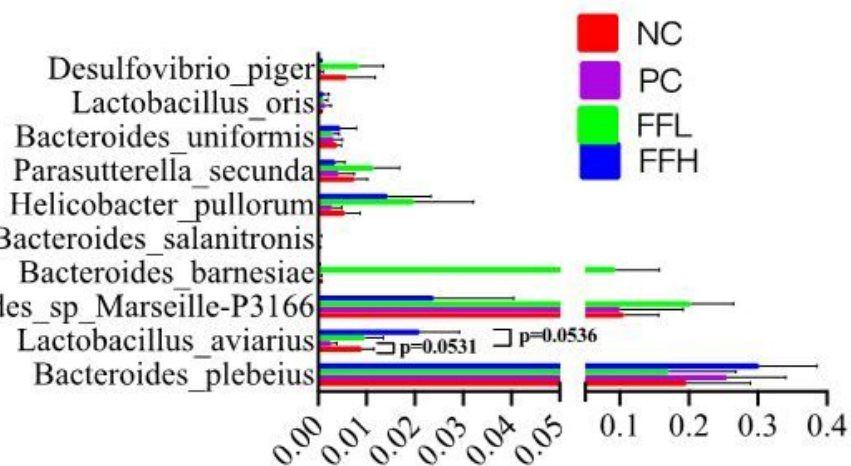

\section{Figure 6}

Effect of antibiotic and fermented feed on the H-test bar plot on phylum, class, order, family, genus, and species level of broiler chickens. Negative control (NC), Positive control (Antibiotic) (PC), Fermented feed (low dose) (FFL), Fermented feed (high dose) (FFH). The bacterial clades showing differences at phylum, class, order, family, genus, and species levels in different treatment groups and control groups. (A) bacterial clades significantly different at the phylum level in different groups $(P<0.05$ is showing significant difference). (B) bacterial clades significantly different at the class level in different groups ( $\mathrm{P}<$ 0.05 is showing significant difference). (C) bacterial clades significantly different at the order level in different groups ( $P<0.05$ is showing significant difference $)$. (D) bacterial clades significantly different at the family level in different groups $(P<0.05$ is showing significant difference). ( $E$ ) bacterial clades significantly different at the genus level in different groups $(P<0.05$ is showing significant difference). $(F)$ bacterial clades significantly different at the species level in different groups $(P<0.05$ is showing significant difference). 